$\xi^{2}=-1$

\title{
Impact of alley cropping system on soil fertility
}

\author{
Jannatul Ferdush ${ }^{1}{ }^{*}$, Md. Meftahul Karim ${ }^{1}$, Iffat Jahan Noor ${ }^{1}$, Sadia Afrin Jui ${ }^{1}$, \\ Tofayel Ahamed ${ }^{2}$, Dr. Sataya Ranjan Saha ${ }^{2}$ \\ ${ }^{1}$ Scientific Officer, Bangladesh Jute Research Institute, Manik Mia Avenue, Dhaka-1207 \\ ${ }^{2}$ Professor, Department of Agroforesty \& Environment, Bangabandhu Sheikh Mujibur Rahman Agricultural University \\ *Corresponding author E-mail: jannatmukta78@gmail.com
}

\begin{abstract}
A field experiment was conducted to investigate the effect of pruned materials of two hedgerow species on wheat production and soil nutrient changes at different nitrogen levels in the research farm of the Bangabandhu Shiekh Mujibur Rahman Agricultural University (BSMARU) during November 2012 to March 2013. The design of the experiment was split plot, where two multipurpose tree species (MPTS) namely Gliricidia sepium and Leucaena leucocephala were arranged in main plots and five different doses of nitrogen (0, 25, 50, 75 and $100 \%$ of recommended dose) with pruned materials were distributed to sub plots. Alley widths of both tree species were 6.0 meter. There were also control plots where full dose of recommended nitrogen was applied but no pruned material (PM) was incorporated. The soil chemical properties in the alleys consisting of G. sepium and L. leucocephala responded differently. Positive changes in the soil fertility in terms of soil $\mathrm{pH}$, organic $\mathrm{C}$, total $\mathrm{N}$, available $\mathrm{P}$, available $\mathrm{S}$ and exchangeable $\mathrm{Ca}, \mathrm{Mg}, \mathrm{K}$ and $\mathrm{CEC}$ of the top soil layer were observed in alley cropping system. Pruned materials application substantially reduced the nitrogen requirement for wheat production and $50 \%$ Nitrogen fertilizer could be saved through pruned materials application. Among the tree species G. sepium seemed to be superior over L. leucocephala in building soil health.
\end{abstract}

Keywords: Alley Cropping; Hedgerow; Pruning; Soil Fertility; Ph.

\section{Introduction}

Bangladesh is a small deltaic country with a large population of 161 million with cultivable land of 8.44 million ha is being used for agricultural purpose which has low productivity due to the poor soil health. Due to intensive cultivation, soil fertility is reducing rapidly, and consequently reducing the crop yield. As a result, the natural soil ecosystem has rapidly degrading and farm agro-ecosystem losing its integrity and health as well as polluting the environment. The organic matter content which is an indicator of soil health is depleted to less than critical value of 1 percent (Hossain and Kashem, 1997) in most of the areas (about 60 percent) of cultivable land during the last 20-25 years. Now-a-days, alley cropping is considered as an ideal technology for sustainable crop production where agricultural crops are grown in the inter-space between rows of planted shrubs/tree species, preferably legumes, which are periodically pruned to minimized tree-crop competition for growth resources such as water, nutrient and light (Tossah et al., 1999). Pruned materials are applied in soil for releasing nutrients to improve the growth and development of associated crops through improving the physiochemical characteristics of soils (Miah, 1993). In addition, fast growing leguminous trees/shrubs species are grown because it usually recycles nutrients, contribute biological nitrogen fixation (Kang et al., 1994). Among the evaluated tree species for alley cropping Gliricidia sepium and Leucaena leucocephala are the two most suitable species which are used in alley cropping in many parts of the world. These two species biologically fix N, can be established easily by direct seeding, withstand repeated pruning, produce large amounts of biomass. Any nitrogenous fertilizer saving by maintaining the crop productivity through alley cropping system would be immense value particularly for the resource poor farmers of Bangladesh. This information will help the farmers for reducing their production cost. Eventually, it will be considered as suitable technology both economically and environmentally.

In view of the above circumstances, a study was undertaken with the following objectives:

To examine the soil fertility status influenced by alley cropping system.

\section{Materials and methods}

\subsection{Description of experimental site and duration}

The experiment was conducted at the Bangabandhu Sheikh Mujibur Rahman Agricultural University (BSMARU) research farm of the Department of Agroforestry and Environment, Gazipur.

\subsection{Soil}


The experimental soil was originally shallow red brown terrace under Salna Series (Brammer, 1978) in Madhupur Tract (AEZ 28).

\subsection{Experimental design and treatment}

The experimental was laid out in a split-plot design, with three replications. Tree species were arranged in main plots and different doses of nitrogen were distributed into sub plot. Tree species used in main plots were as follows:

Factor A: Two tree species with control

- $\quad$ Gliricidia sepium (G. sepium)

- Leucaena leucocephala (L. leucocephala)

- Control (Without tree species)

Factor B: Nitrogen levels (5)

- $\quad \mathrm{N} 0$ (zero dose of N) + Pruned materials (PM)

- $\quad \mathrm{N} 25(25 \%$ of recommended $\mathrm{N}$ dose $)+\mathrm{PM}$

- $\quad \mathrm{N} 50(50 \%$ of recommended $\mathrm{N}$ dose $)+\mathrm{PM}$

- $\quad \mathrm{N} 75$ (75\% of recommended $\mathrm{N}$ dose $)+\mathrm{PM}$

- $\quad \mathrm{N} 100(100 \%$ of recommended N dose $)+$ PM

The alley width was $6.0 \mathrm{~m}$. Every alley was divided into 15 unit plots comprising three replications and five levels of nitrogen. The unit plot length was $5 \mathrm{~m}$. So, total area of a unit plot was $6 \mathrm{~m} \times 5 \mathrm{~m}$.

There were a control treatments which received recommended nitrogen dose but no pruned material was used for growing crops to compare the results with crop yields under alley cropping system. Urea was used as the source of different nitrogen doses.

\subsection{Soil sample collection and chemical analysis}

Soils from different positions were collected before starting of the experiment and immediately after harvesting of the crops from $\mathrm{N}_{0+}$ PM, N $\mathrm{N}_{25}+\mathrm{PM}, \mathrm{N}_{50}+\mathrm{PM}, \mathrm{N}_{75}+\mathrm{PM}, \mathrm{N}_{100}+\mathrm{PM}$ treated plots. Before starting the experiment, soil samples were collected from different part of the alley of the experimental field and then mixed together to make composite samples. Immediately after crop harvest, the soil samples were collected from $\mathrm{N}_{0}, \mathrm{~N}_{25}, \mathrm{~N}_{50}, \mathrm{~N}_{75}$ and $\mathrm{N}_{100}$ plus pruned materials added plots. In each case, soil samples were taken from the $0-15 \mathrm{~cm}$ depth. The collected soil samples were then air dried, ground, sieved and used for chemical analysis. Chemical analysis was done for $\mathrm{pH}$, organic carbon, total nitrogen, available phosphorus, available sulfur, exchangeable calcium, magnesium, potassium and cation exchange capacity (CEC). The above analyses were done using the following methods:

\subsubsection{Soil pH}

Soil $\mathrm{pH}$ was measured using glass electrode $\mathrm{pH}$ meter as described by Jackson (1985). Soil-water mixture was made in the ratio of 1: 2.5 .

\subsubsection{Organic carbon}

Organic carbon was estimated using wet oxidation method.

\subsubsection{Total nitrogen}

Total nitrogen was measured using micro-kjeldahl method following $\mathrm{H}_{2} \mathrm{SO}_{4}$ digestion and steam distillation with $\mathrm{NaOH}$. Ammonia thus collected in boric acid was determined by titration with $0.02 \mathrm{~N} \mathrm{H}_{2} \mathrm{SO}_{4}$.

\subsubsection{Available phosphorus}

Available phosphorus was measured using Molybdenum Blue method at $710 \mathrm{~nm}$ by Double Beam Spectrophotometer.

\subsubsection{Exchangeable $\mathrm{K}$ and $\mathrm{Ca}$}

Exchangeable $\mathrm{K}$ and $\mathrm{Ca}$ were measured using Atomic Absorption Spectrophotometer. Solution of $1 \mathrm{M}$ ammonium acetate was added to air dried soil and allowed to stay overnight. The supernatant was repeatedly collected to allow the exchangeable cations to be exchanged from the soil particles with $\mathrm{NH}_{4}{ }^{+}$cations. The absorbance were measured at wavelength of $766.5 \mathrm{~nm}$ for K, $422.8 \mathrm{~nm}$ for Ca and 285.2 $\mathrm{nm}$ for $\mathrm{Mg}$ respectively by Atomic Absorption Spectrophotometer.

\subsubsection{Available sulfur (ppm)}

Available sulfur was determined turbidimetrically as barium sulfate. The method was that of Chesin and Yien (1951).

\subsubsection{Cation exchange capacity (CEC)}

Ammonium acetate solution was added to air dried soil and allowed to stay overnight. After centrifugation, the supernant was decanted and this was repeated to allow the exchangeable cation to be exchanged from the soil particles with $\mathrm{NH}_{4}{ }^{+}$cation. The soil was washed with $80 \%$ ethanol. Then $1 \mathrm{M} \mathrm{NaCl}$ was added with soil and washed for 5 times and was centrifuged. After treating, with $1 \mathrm{M} \mathrm{NaCl}$ solution the supernant was collected and allowed to distillation and titration.

\subsection{Statistical analysis}

The data relating to growth yield and yield contributing characters of wheat and tree performance were subjected to analysis of variation (ANOVA) with the help of computer "MSTATC" program. Analysis of variance was done according to Gomez and Gomez (1984). 


\section{Results and discussion}

\subsection{Total nitrogen in soil}

Nitrogen, the most limiting nutrient for crop production did not vary in soils with the tree species planted (Figure 2). However, total soil nitrogen in L. leucocephala alley was found slightly higher than G. sepium alley, which might be due to higher leaf nitrogen content in $L$. leucocephala.

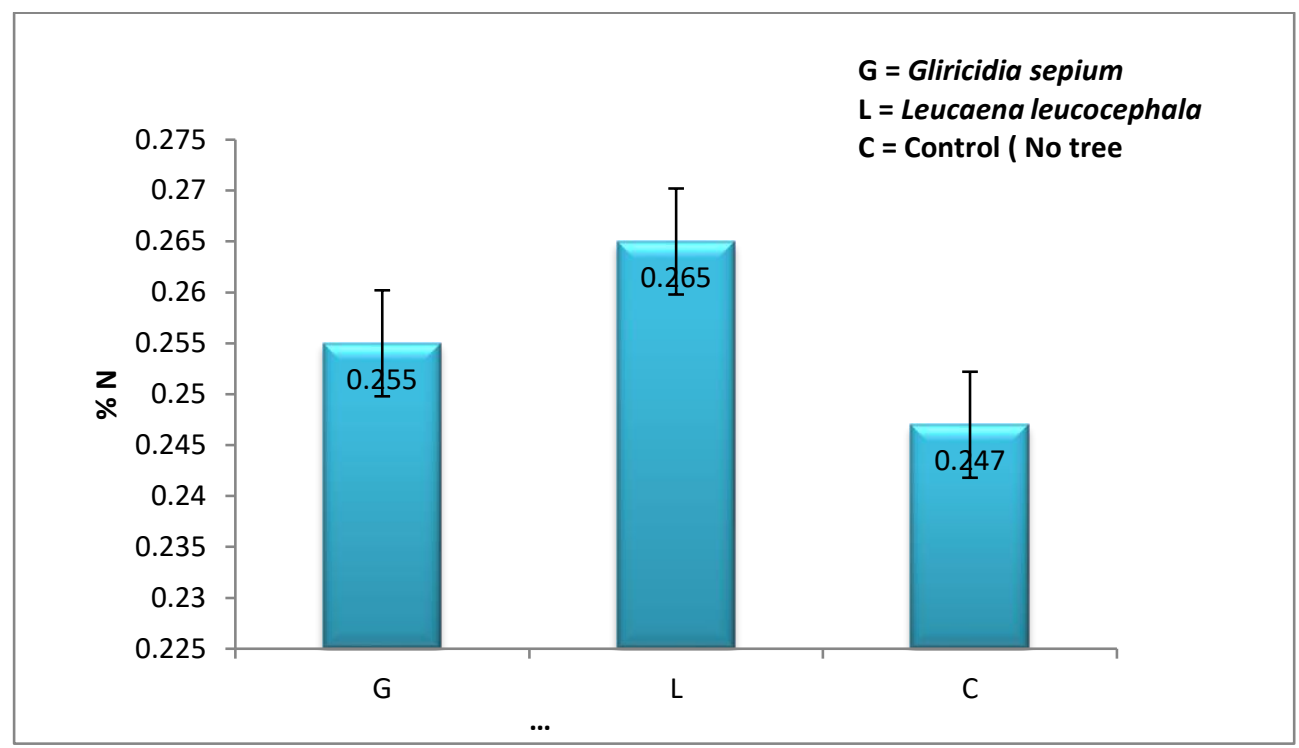

Fig. 1: Nitrogen Status in Alley Cropping Systems as Influenced by Tree Pruned Materials of Two Different Tree Species after Harvesting of Wheat.

The effect of nitrogen fertilizer plus pruned materials application and the interaction of nitrogen fertilizer and tree species did not show significant effects. In general, highest soil nitrogen $(0.263 \%)$ was found in $\mathrm{N}_{100}+\mathrm{PM}$ and $\mathrm{N}_{75}+\mathrm{PM}$ and the lowest $(0.242 \%)$ was found in $\mathrm{N}_{25}+\mathrm{PM}$ (Fig.3).

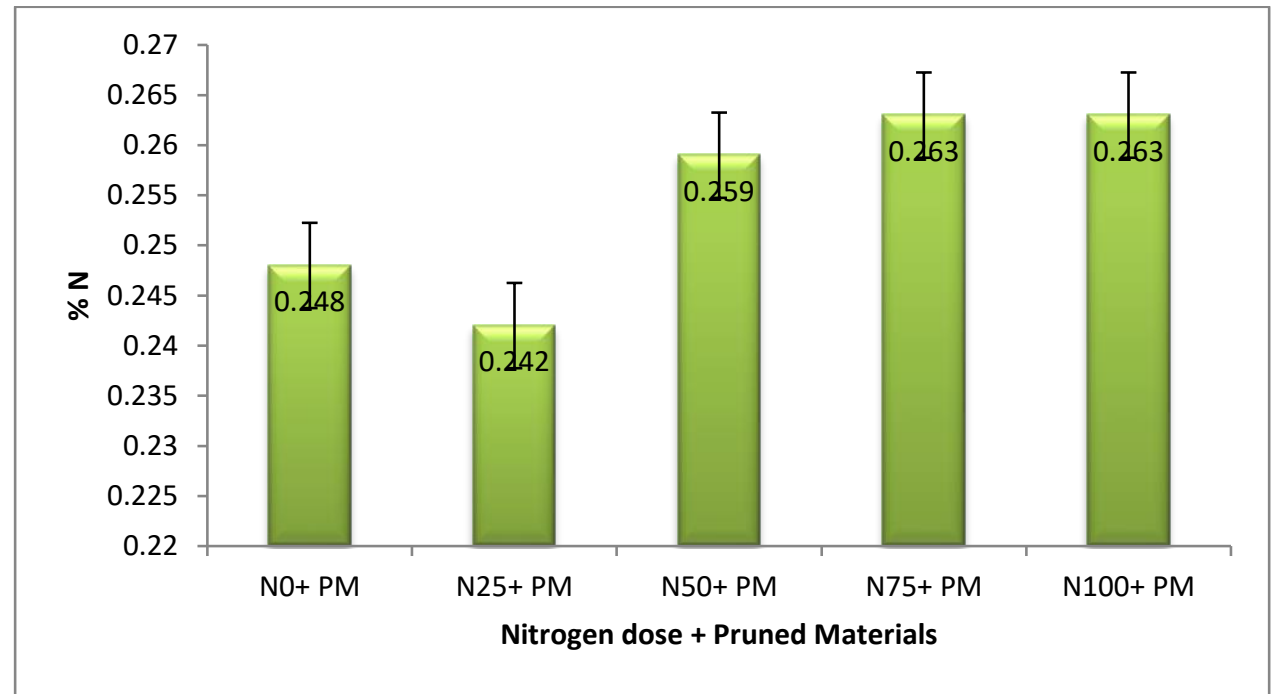

Fig. 2: Nitrogen Status in Alley Cropping Systems as Influenced by Tree Pruned Materials of Two Different Tree Species Along with Different N Doses after Harvesting of Wheat.

In case of interaction of nitrogen fertilizer and tree species (Table 1) the highest soil nitrogen $(0.269 \%)$ was found in $\mathrm{N}_{50} \times \mathrm{LL}, \mathrm{N}_{75} \times \mathrm{LL}$ and $\mathrm{N}_{25} \times \mathrm{GS}$ and the lowest $(0.231 \%)$ was found in $\mathrm{N}_{100} \times \mathrm{C}$ combination.

Table 1: Nitrogen Status in Alley Cropping Systems as Influenced by Tree Pruned Materials of Two Different Tree Species Along with Different N Doses after Harvesting of Wheat

\begin{tabular}{lc}
\hline Treatment & Total N $(\%)$ \\
\hline Nitrogen $\times$ tree species & \\
$\mathrm{N}_{0} \times \mathrm{GS}$ & 0.249 \\
$\mathrm{~N}_{25} \times \mathrm{GS}$ & 0.269 \\
$\mathrm{~N}_{50} \times \mathrm{GS}$ & 0.250 \\
$\mathrm{~N}_{75} \times \mathrm{GS}$ & 0.240 \\
$\mathrm{~N}_{100} \times \mathrm{GS}$ & 0.265 \\
$\mathrm{~N}_{0} \times \mathrm{LL}$ & 0.240 \\
$\mathrm{~N}_{25} \times \mathrm{LL}$ & 0.250 \\
$\mathrm{~N}_{50} \times \mathrm{LL}$ & 0.269 \\
\hline
\end{tabular}




\begin{tabular}{ll}
\hline $\mathrm{N}_{75} \times \mathrm{LL}$ & 0.269 \\
$\mathrm{~N}_{100} \times \mathrm{LL}$ & 0.255 \\
$\mathrm{~N}_{0} \times \mathrm{C}$ & 0.240 \\
$\mathrm{~N}_{25} \times \mathrm{C}$ & 0.240 \\
$\mathrm{~N}_{50} \times \mathrm{C}$ & 0.240 \\
$\mathrm{~N}_{75} \times \mathrm{C}$ & 0.240 \\
$\mathrm{~N}_{100} \times \mathrm{C}$ & 0.231 \\
\hline
\end{tabular}

In a column, means followed by a common small letter are not significantly different at the 5\% level by DMRT.

$\mathrm{GS}=$ Gliricidia sepium, $\mathrm{LL}=$ Leucaena leucocephala

$\mathrm{N}_{0}=0 \%$ Nitrogen, $\mathrm{N}_{25}=25 \%$ Nitrogen, $\mathrm{N}_{50}=50 \%$ Nitrogen, $\mathrm{N}_{75}=75 \%$ Nitrogen and $\mathrm{N}_{100}=100 \% \mathrm{Nitrogen}$.

The interaction effect of nitrogen fertilizer and tree species on soil nitrogen was found the significantly highest $(0.18 \%)$ when nitrogen fertilizer was applied at the rate of $75 \mathrm{~kg} \mathrm{~N} \mathrm{ha}^{-1}$ in L. leucocephala alley, which is still low in terms of soil fertility ranking (BARC, 2005). Nitrogen loss from the soil environment is very high through different pathways like denitrification, ammonia volatilization, nitrate leaching etc. Therefore, enrichment of soil with nitrogen and storing for long time is not possible. Judicious and balanced application of nitrogen as per crop requirements is always advisable for better utilization of nitrogen in crop production. Increased $\mathrm{N}$ content of the surface soil with leguminous trees was reported by Getahun and Jama (1989).

\subsection{Soil pH}

The soil $\mathrm{P}^{\mathrm{H}}$ did not vary among the treatments (Table 2). Incorporating the pruning materials slightly increased the soil $\mathrm{p}^{\mathrm{H}}$. Among the treatment, the highest soil $\mathrm{p}^{\mathrm{H}}$ was recorded in $\mathrm{GS}+\mathrm{N}_{0}(6.6)$ and the lowest was in $\mathrm{CC}+\mathrm{N}_{0}(5.7)$. The increased soil $\mathrm{p}^{\mathrm{H}}$ by $G$. sepium may be explained by its faster leaf decomposition (Miah et al. 1997) and higher foliar Ca levels. Similar increase in soil $\mathrm{p}^{\mathrm{H}}$ under $G$. sepium was observed by other scientists (Miah 1993, Gavine 1989, Alla-Krah and Sumberg 1987, Onim et al. 1990).

\subsection{Organic carbon}

Changes in organic carbon as a result of different treatments showed that soil organic carbon content in the control plot was slightly lower, but higher in all other plots (Table 2). The highest amount of organic carbon was recorded in GS+N $\mathrm{N}_{100}(1.4 \%)$ and $\mathrm{GS}+\mathrm{N}_{25}(1.4 \%)$. The lowest amount of organic carbon was found in $\mathrm{CC}+\mathrm{N}_{25}$ (1.1). Alla- Khra and Sumberg (1987) found $1.59 \%$ organic carbon with $G$. sepium compared to $1.13 \%$ without $G$. sepium. Miah et al. (1997) found $0.983 \%$ organic carbon with G. sepium compared to $0.847 \%$ without G. sepium.

\subsection{Available $P$}

Available phosphorus means the portion of the total soil phosphorus which can be utilized by plants and that can be extracted by dilute acid solution. Most of the natural ecosystem, P level of soil is low. But soils with tree species showed increased available $\mathrm{P}$ content. Among the all treatments, the highest available $\mathrm{P}$ was obtained from $\mathrm{GS}+\mathrm{N}_{0}(7.01 \mathrm{ppm})$ and the lowest was obtained from $\mathrm{CC}+\mathrm{N}_{0}(5.00$ $\mathrm{ppm})$.

Table 2: Soil $\mathrm{P}^{\mathrm{H}}$, Organic Carbon \& CEC Status in Alley Cropping Systems as Influenced by Tree Pruned Materials of Three Different Species Along With Different N Doses after Harvesting of Wheat

\begin{tabular}{llll}
\hline Treatment & PH & Organic C (\%) & CEC (MEQ/100g) \\
\hline GS + No & 6.6 & 1.2 & 13.46 \\
GS + N25 & 6.2 & 1.4 & 14.28 \\
GS + N50 & 6.1 & 1.3 & 14.56 \\
GS + N75 & 6.2 & 1.3 & 13.46 \\
GS + N100 & 6.4 & 1.4 & 14.28 \\
LL + No & 6.2 & 1.2 & 13.18 \\
LL + N25 & 6.3 & 1.2 & 13.73 \\
LL + N50 & 6.2 & 1.3 & 14.01 \\
LL + N75 & 6.0 & 1.3 & 14.56 \\
LL + N100 & 6.0 & 1.2 & 13.18 \\
CC + No & 5.7 & 1.1 & 1.54 \\
CC + N25 & 5.8 & 1.3 & 12.66 \\
CC + N50 & 5.9 & 1.3 & 12.63 \\
CC + N75 & 6.2 & 1.2 & 10.71 \\
CC + N100 & 5.8 & & 12.36 \\
\hline
\end{tabular}

\subsection{Exchangeable $\mathrm{K}$}

The exchangeable $\mathrm{K}$ content showed an irregular fashion however it was lower in control treatment compared to agroforestry treatments (Table 11). Crop removal and losses through runoff may be attributed the lowest exchangeable $\mathrm{K}$ in control plot moreover no $\mathrm{K}$ added to this plot through pruned materials, whereas, the increase in exchangeable $\mathrm{K}$ in plots with tree species was probably due to the return of $\mathrm{K}$ via tree pruning and leaf litter fall to the soil surface (Miah et al., 1997). Results showed that the highest K content was found in GS+N 25 $(0.22 \mathrm{meq} / 100 \mathrm{~g}) \& \mathrm{GS}+\mathrm{N}_{50}(0.22 \mathrm{meq} / 100 \mathrm{~g})$ and the lowest was found in $\mathrm{CC}+\mathrm{N}_{25}(0.12 \mathrm{meq} / 100 \mathrm{~g})$. Increased exchangeable $\mathrm{K}$ was observed under G. sepium by Gonzal and Raros (1987). The present findings are in agreement with that of Gonzal and Raros, (1987), Lasco (1991), and Miah et al. (1993). 
Table 3: Soil Available P, Exchangeable Bases (K \& Ca) \& S Status in Alley Cropping Systems as Influenced by Tree Pruned Materials of Three Different Species Along with Different N Doses after Harvesting of Wheat

\begin{tabular}{|c|c|c|c|c|}
\hline Treatment & Available P (ppm) & $\begin{array}{l}\text { Exch } \\
\text { K }\end{array}$ & $\mathrm{Ca}$ & $\mathrm{S}(\mathrm{ppm})$ \\
\hline $\mathrm{GS}+\mathrm{N}_{\mathrm{o}}$ & 7.01 & 0.18 & 5.48 & 9.36 \\
\hline $\mathrm{GS}+\mathrm{N}_{25}$ & 6.64 & 0.22 & 6.14 & 12.98 \\
\hline $\mathrm{GS}+\mathrm{N}_{75}$ & 6.67 & 0.20 & 6.27 & 11.77 \\
\hline $\mathrm{GS}+\mathrm{N}_{100}$ & 6.56 & 0.20 & 5.72 & 10.87 \\
\hline $\mathrm{LL}+\mathrm{N}_{\mathrm{o}}$ & 6.78 & 0.16 & 5.41 & 9.66 \\
\hline $\mathrm{LL}+\mathrm{N}_{25}$ & 6.64 & 0.17 & 5.34 & 9.96 \\
\hline $\mathrm{LL}+\mathrm{N}_{75}$ & 7.30 & 0.19 & 4.58 & 11.47 \\
\hline $\mathrm{LL}+\mathrm{N}_{100}$ & 6.48 & 0.19 & 4.71 & 11.77 \\
\hline $\mathrm{CC}+\mathrm{N}_{\mathrm{o}}$ & 5.00 & 0.15 & 5.30 & 9.06 \\
\hline $\mathrm{CC}+\mathrm{N}_{25}$ & 5.25 & 0.12 & 4.99 & 10.87 \\
\hline $\mathrm{CC}+\mathrm{N}_{50}$ & 5.25 & 0.16 & 4.78 & 8.15 \\
\hline $\mathrm{CC}+\mathrm{N}_{75}$ & 5.58 & 0.12 & 4.78 & 7.25 \\
\hline $\mathrm{CC}+\mathrm{N}_{100}$ & 5.08 & 0.16 & 4.58 & 12.68 \\
\hline
\end{tabular}

\subsection{Exchangeable Ca}

The exchangeable Ca contents of soil showed an increasing trend in all agroforestry treatments (Table 11). Among the treatments, the highest amount of exchangeable $\mathrm{Ca}$ was found in $\mathrm{GS}+\mathrm{N}_{75}(6.27 \mathrm{meq} / 100 \mathrm{~g})$ and lowest was recorded in $\mathrm{CC}+\mathrm{N}_{100}(4.58 \mathrm{meq} / 100 \mathrm{~g})$. The overall exchangeable $\mathrm{Ca}$ value was higher in $G$. sepium tree species followed by L. leucocephala. Similar results regarding increase of soil Ca in agroforestry systems have been reported in other experiments (Miah et al. 1997, Lal 1989, Onim et al. 1990, Soriano 1991).

\subsection{Cation exchange capacity}

The variations of CEC of the soil before and after the experiment were not so distinct (Table 11). The CEC in control plot decreased slightly, but increased in all other treatments. However, the overall highest CEC was observed under G. sepium (13.46, 14.28, 14.56, 13.46 and $14.28 \mathrm{meq} / 100 \mathrm{~g}$ in $\mathrm{GS}+\mathrm{N}_{0}, \mathrm{GS}+\mathrm{N}_{25}, \mathrm{GS}+\mathrm{N}_{50}, \mathrm{GS}+\mathrm{N}_{75}$ and $\mathrm{GS}+\mathrm{N}_{100}$ treatments respectively) and the lowest was recorded in control plots $\left(11.54,12.66,12.63,10.71\right.$ and 12.36 meq/100g in $\mathrm{CC}+\mathrm{N}_{0}, \mathrm{CC}+\mathrm{N}_{25}, \mathrm{CC}+\mathrm{N}_{50}, \mathrm{CC}+\mathrm{N}_{75}$ and $\mathrm{CC}+\mathrm{N}_{100}$ treatments respectively).

\subsection{Sulfur}

Among all the treatments overall higher amount of $\mathrm{S}$ was observed under $\mathrm{G}$. sepium $(9.36,12.98,11.17,11.77$ and $10.87 \mathrm{meq} / 100 \mathrm{~g}$ in $\mathrm{GS}+\mathrm{N}_{0}, \mathrm{GS}+\mathrm{N}_{25}, \mathrm{GS}+\mathrm{N}_{50}, \mathrm{GS}+\mathrm{N}_{75}$ and $\mathrm{GS}+\mathrm{N}_{100}$ treatments respectively) and lower amount was recorded in control plots (9.06, 10.87, $8.15,7.25$ and 12.68 meq/100g in $\mathrm{CC}+\mathrm{N}_{0}, \mathrm{CC}+\mathrm{N}_{25}, \mathrm{CC}+\mathrm{N}_{50}, \mathrm{CC}+\mathrm{N}_{75}$ and $\mathrm{CC}+\mathrm{N}_{100}$ treatments respectively).

\section{Conclusion}

Accomplishing the present investigation, it may be concluded that In this alley cropping system the soil properties in the top layer changed in a positive direction in respect of soil $\mathrm{pH}$, organic carbon, total $\mathrm{N}$, available $\mathrm{P}$, available $\mathrm{S}$, exchangeable $\mathrm{K}, \mathrm{Ca}$ and $\mathrm{CEC}$ compared to control. The degree of suitability of the two tree species in terms of crop productivity and soil properties may be ranked as Gliricidia sepium > Leucaena leucocephala.

\section{Conflict of interest statement}

All the authors do not have any conflict with respect to research, authorship or publications of this article.

\section{Acknowledgements}

The author expresses thanks and gratitude to all the persons of Department of Agroforestry \& Environment and Soil Science of Bangabandhu Sheikh Mujibur Rahman Agricultural University for their patience and sincere help in laboratory anlaysis. The author also expresses her heartiest gratitude to all co-authors for their important technical as well as practical assistance in data collection, analysis and reporting regarding this research work.

\section{References}

[1] BARC. 2005. Fertilizer Recommendation Guide-2005, Bangladesh Agricultural Research Council, Dhaka, Bangladesh.

[2] Brammer, H. 1978. Soil Resources. Soil Survey Project Bangladesh. Agl. St. Pak.6. Technical Reports. UNDP/FAO.

[3] Chesin, L. and C.H. Yien. 1951. Turbidimetric determination of available sulfates. Soil Sci. Soc. Am. Proc. 15: 149-151 https://doi.org/10.2136/sssaj1951.036159950015000C0032x.

[4] Getahun, A. and B. Jama. 1986. Alley cropping in the coastal area of Kenya. In: Proceedings of workshop on alley Farming in the Humid and Subhumid Tropics held at Ibadan, Nigeria, 10-14 March 1989.

[5] Gavine, L.B. 1989. Preliminary assessment of nutrient contents of soil under Gliricidia sepium. Nitrogen fixing Tree Research Reports, 7:94.

[6] Hossain, S.B., and M.A. Kashem. 1997. Management combat declining soil fertility in Bangladesh. Keynote paper. Proceeding of the $6^{\text {th }}$ Biennial Conference of the Bangladesh Society of Agronomy. Held on 29 July 1997. pp: 22-39.

[7] Kang, B.T., T. Grimme and T.L. Lawson. 1994. Alley cropping sequentially cropped maize and cowpea with leucaena on a sandy soil in Southern Nigeria. Plant and Soil 63: 165-179. https://doi.org/10.1007/BF02374595. 
[8] Lal, R. 1989. Agroforestry system and soil surface management of a tropical alfisol: In: Soil moisture and crop yields. Agroforestry Systems 8: 729. https://doi.org/10.1007/BF00159066.

[9] Miah, M.G. 1993. Performance of selected multipurpose tree species and field crops grown in association as affected by tree branch pruning. Ph.D. dissertation Research. CLSU, Philippines.

[10] Miah, M.G., D.P. Garrity and M.L. Aragon. 1997. Effect of legume trees on soil chemical properties under agroforestry system. Ann. Bangladesh Agric. 7(2):95-103.

[11] Onim, J.F.M., M. Mathuva, K. Otieno and Fitzhugh. 1990. Soil fertility changes and response of maize and beans to green manure of leucaena, sesbania and pigeonpea. Agroforestry Systems, 12: 197-215. https://doi.org/10.1007/BF00123474.

[12] Soriano, H.M.Jr. 1991. Soil fertility and productivity aspects of alley cropping schemes using leguminous trees as hedgerows and corn. As an alley crop. A Ph. D disseretation, UPLB, Laguna.

[13] Tossah, B.K., D.K. Zamba, B. Vanlauwe, N. Sanginga, O. Lyasse, J. Diels and R. Merckx. 1999. Alley cropping in the moist savanna of West Africa: Impact on soil productivity in a north to south transects in Togo. Agroforestry Systems: 42(3):229-244. https://doi.org/10.1023/A:1006124317003. 